\title{
Magnetic Resonance Imaging Findings of the Asymptomatic Shoulder May Impact Performance, Not Future Injury List Placement in Major League Baseball Pitchers
}

\author{
Alexander Beletsky, M.D., Kelechi R. Okoroha, M.D., Brandon Cabarcas, M.D., \\ Grant H. Garcia, M.D., Anirudh K. Gowd, M.D., John Meyer, M.D., Amar S. Vadhera, B.S., \\ Harsh Singh, B.A., Safa Gursoy, M.D., Ph.D., Gregory M. White, M.D., \\ James Davidson, M.D., Gregory P. Nicholson, M.D., Jorge Chahla, M.D., Ph.D., and \\ Nikhil N. Verma, M.D.
}

\begin{abstract}
Purpose: To evaluate preseason shoulder magnetic resonance images (MRIs) obtained from pitchers entering either major or minor league baseball (MLB) and correlate findings with subsequent injury, operative repair, and placement on the injured list (IL). Methods: Preseason-MRI of the throwing shoulders of professional-level baseball pitchers, taken during routine evaluations at a single organization (2004-2017) were retrospectively reviewed. Publicly available databases were queried to exclude pitchers with known injuries prior to pre-signing imaging. Three blinded reviewers reviewed all MRI scans independently to evaluate for the presence of abnormalities in the rotator cuff (RTC), labrum, capsule, long-head of the biceps tendon (LHBT), and humeral head. Binary imaging findings were correlated to future placement on the IL for subsequent shoulder complaints. Bivariate statistics using Student's $t$-tests and Fisher exact tests (both $\alpha=.05$ ) were used in this study. Results: A total of 38 asymptomatic pitchers with shoulder MRIs were included. Pitchers had a mean $( \pm \mathrm{SD})$ age of $28.2 \pm 4.9$ and had pitched an average of $119.6 \pm 143.8$ career games. Pitchers with partial articular-sided RTC tears $(P=.04)$ or intra-articular BT hyperintensity $(P=.04)$ on preseason MRI demonstrated an association with the need for future surgery. Pitchers with evidence of labral heterogeneity demonstrated greater total career pitch counts $(10,034.1$ vs $2,465.3 ; P=.04)$. Evidence of a posterior-superior humeral cyst was associated with decreased strikeouts per 9 innings $(6.1$ vs $8.0 ; P=.039)$ and total strikeout percentage $(16.1 \%$ vs $23.2 \% ; P=.04)$. Conclusion: Although there was a significant difference in the percent of various radiographic findings between the injured and healthy cohort, no MRI findings were predictive of future IL placement or duration of placement. The presence of a posterior superior humeral cyst was associated with decreased strikeout rates at 2 and 3 years, the presence of a labral tear was associated with decreased earned run average (ERA) at 3 years and decreased career strikeout percentages, and increased capsular signal was associated with decreased 5-year ERA. Level of Evidence: Level IV, retrospective study.
\end{abstract}

University of California, San Diego School of Medicine, La Jolla, CA U.S.A. (A.B.); OrthoArizona, Phoenix, Arizona, U.S.A. (J.D.); and Division of Sports Medicine, Midwest Orthopaedics at Rush, Rush University Medical Center, Chicago, IL, U.S.A. (K.R.O., B.C., G.H.G., A.K.G., J.M., A.S.V., H.S., S.G., G.M.W., G.P.N., J.C., N.N.V.).

The authors report the following potential conflicts of interest or sources of funding: G.C. reports being a paid consultant for Arthrex, Inc., CONMED Linvatec, Ossur, and Smith $\theta$ Nephew. G.P.N. reports receiving royalties from Innomed and Wright Medical Technology, Inc.; is a paid presenter for Arthrosurface; and is a paid consultant for Tornier and Wright Medical Technology, Inc. N.N.V. reports being a board/committee member of the American Orthopaedic Society for Sports Medicine and the American Shoulder and Elbow Surgeons, and is on the editorial or governing board of Knee and SLACK, Inc. He has received research support from Arthrex, Breg, Ossur, Smith $\theta$ Nephew, and Wright Medical Technology, Inc.; has stock or stock options from Minivasive and Cymedica; is a paid consultant for Minivasive and Orthospace; has received financial or material support from Arthroscopy and Vindico Medical-Orthopedics Hyperguide, outside the submitted work. Full ICMJE author disclosure forms are available for this article online, as supplementary material.

Received June 5, 2021; accepted October 11, 2021.

Address correspondence to Nikhil N. Verma, M.D., Midwest Orthopaedics at Rush, 1611 W Harrison St., Chicago, IL, 60661, U.S.A. E-mail: Nikhil. verma@rushortho.com

(C) 2021 THE AUTHORS. Published by Elsevier Inc. on behalf of the Arthroscopy Association of North America. This is an open access article under the CC BY-NC-ND license (http://creativecommons.org/licenses/by-nc-nd/4.0/). 2666-061X/21825

https://doi.org/10.1016/j.asmr.2021.10.029 


\section{Introduction}

$\mathbf{M}$ ajor league baseball (MLB) pitchers use highspeed and complex overhead motions in order to pitch at the professional level; however, this motion introduces a significant strain on the arm of the pitcher. ${ }^{1-3}$ The balance between sufficient laxity to maximize extremes of motion and velocity and adequate stability to prevent subluxation has been referred to as the "throwers paradox." ${ }^{2,4}$ In this population, common elbow injury patterns include pathology of the ulnar collateral ligament (UCL) and in the shoulder, injuries to the rotator cuff (RTC), glenoid labrum, and biceps tendon. ${ }^{5}$ As might be expected, pitchers are most likely to be put on the injured list (IL) due to injury of the throwing shoulder. ${ }^{6}$

Time lost on the IL comes at a significant financial cost. In 2018, annual salaries of major league pitchers totaled approximately $\$ 1.5$ billion, suggesting that pitchers present the largest financial burden with respect to players placed on the IL..$^{6-8}$ Therefore, there is both a competitive and financial incentive to ensure the health, well-being, and performance of these athletes. This has resulted in significant athletic efforts and team resources being dedicated to predicting risk of injury over the course of an athlete's career. ${ }^{9}$ Previous literature has suggested that evaluated pitch counts, ${ }^{9-12}$ pitch velocity, ${ }^{13,14}$ and preseason range of motion (ROM) ${ }^{15}$ may be modulated in an attempt to provide guidelines to diminish risk of injury. Despite its expense, preseason magnetic resonance imaging (MRI) of asymptomatic athletes has also been employed as a tool for prediction in both MLB and other competitive sports. ${ }^{7,16-18}$

Magnetic resonance imaging is the most sensitive modality for identifying soft tissue shoulder pathology. However, the utility of indeterminate findings on MRI have yet to be determined. ${ }^{19-21}$ Pathologic findings in asymptomatic shoulders are more prevalent than previously thought, including RTC tears, biceps, and labral lesions; however, these findings have not been correlated with increased rates of IL placement, and have instead been reported to be a function of the number of innings pitched. ${ }^{7,16,22}$ In contrast, MRI findings at the elbow appear to be predictive of injury and have been found to correlate with increased risk of later IL placement, although these results are inconsistent in the literature. ${ }^{23,24}$

Given the inconsistency in the literature, the purpose of this study was to evaluate preseason shoulder MRIs obtained from pitchers entering either major or minor league baseball and correlate findings with subsequent injury, operative repair, and placement on the IL. Our hypothesis is that asymptomatic structural abnormalities found on preseason MRI would correlate with rates of injury, surgery, and time spent on the injured list.

\section{Methods}

\section{Pitcher Selection}

All major and minor league pitchers signed by a single organization from 2005 to 2017 were considered for retrospective review. Pitchers were included if they had an asymptomatic pitching shoulder and had a preseason screening MRI. Pitchers were excluded if they had prior shoulder or elbow surgery, spent any time on the injured list in the last 2 years (i.e., for any injury preventing performance), were symptomatic within the 6 months prior to MRI, or had played less than one full subsequent season in the MLB following return from the IL. Publicly available databases, including "fangraphs.com" 25 and "baseball-reference.com", ${ }^{26}$ were queried for injury and surgical history, prior injured list placement, and baseline patient characteristics. For the purpose of this study, an MRI of asymptomatic shoulder was defined as those performed at least 6 months prior to IL placement for any shoulder-related injury. ${ }^{24}$ Consequently, any pitcher with preseason MRI that preceded injured list placement by less than 6 months was categorized as injured. This led to the creation of an asymptomatic and an injured cohort.

\section{Data Collection}

Relevant data from athlete medical records were abstracted and collected in a custom data table, including nonoperative treatment of a dominant arm injury, duration of placements on the IL, dominant arm surgery, and nonshoulder injuries. Nonmedical information, including draft year, round, and overall pick number, innings pitched, and games started were collected from publicly available data [ESPN]. Other previously mentioned sources ("fangraphs.com" ${ }^{25}$ and "baseballreference.com" ${ }^{26}$ ) were used for tabulation of pitching sabermetrics, including earned-runs average (ERA), batting average on balls in play (BABIP), strikeouts per walk (K/BB), strikeouts per 9 innings of play (K/9), walks plus hits per inning pitched (WHIP), pitches per inning, strikeout and strike zone percentages, percent fastballs, fastball velocity and field-independent pitching. These sabermetric data were aggregated at 1, 2, 3, and 5 years relative to the date of initial MRI. Student's $t$-tests and Fisher exact tests were used to calculate statistically significant differences in sabermetrics between groups. Total career statistics were also collected. Sabermetric statistics were only available for MLB using a combination of PITCHf/x (Sport Vision, Chicago, IL) for data collected after 2007 and Baseball Info Solutions (Coplay, PA) prior to 2007. Sabermetric data were not available for minor league athletes. 


\section{Radiographic Analysis}

Preseason MRI were reviewed and read by three independent reviewers. Reviewers included two fellowship-trained orthopedic sports medicine surgeons and one fellowship-trained musculoskeletal radiologist. Each reviewer was blinded to pitcher identifiers, subsequent performance or injury, or MRI interpretation by the reading radiologist at the time the study was obtained. Five anatomic components of the shoulder were examined in MRI analysis, including the rotator cuff, labrum, capsule, biceps and humeral head. Anatomic structures of interest and rubric of evaluated pathology are listed below (Table 1). The review process consisted of initial radiographic assessment by a fellowship-trained musculoskeletal radiologist and fellowship-trained orthopedic sports medicine surgeon; if there was agreement by both reviewers, no further assessment was needed. In case of disagreement, the third reviewers (a second fellowship-trained orthopedic sports medicine surgeon) acted as a tiebreak. The third reviewer was needed 14 times $(<4 \%$ disagreement rate).

\section{Statistical Analysis}

Statistical analysis was performed using RStudio software version 1.0.143 (R Foundation for Statistical Computing, Vienna, Austria). The injured and healthy cohorts were compared using Student's t-test and when necessary, Fisher exact test. Associations between the radiographic findings and future IL placement were assessed using univariate Fisher exact testing. T-statistics were calculated at $\alpha=.05$ comparing the presence and absence of each radiographic parameter in relation to times on the IL, total length of IL placement, and all pitcher-specific statistics (Table 2).

\section{Results}

A total of 41 pitchers were evaluated from 2005 to 2017 , with the great majority excluded from the current analysis due to either lack of subsequent MLB pitching performance $(n=5)$ or prior time on the injured list (IL) within 2 years $(n=4)$, or surgery within 2 years $(n=3)$. A total of 29 MLB pitchers were included in our retrospective analysis, 7 of which were subsequently placed on the injured IL for shoulderrelated injuries. One pitcher placed on the disabled list required surgery for a subsequent rotator cuff tear with concomitant biceps pathology. Thus, 22 MLB pitchers remained in the "healthy" cohort. With respect to demographics, the injured cohort was significantly older than the healthy cohort $(31.9 \pm 5.0$ vs $27.1 \pm 5.0 ; P=$ $.04)$. There were no significant differences between cohorts with respect to height $(P=.60)$, weight $(P=$ $.68)$, number of games played $(P=.61)$, and handedness $(P=.99)$ (Table 3$)$.

With respect to the MRI findings examined, pitchers who eventually necessitated IL placement had a greater incidence of supraspinatus tendon heterogeneity $(85.7 \%$ vs $68.2 \%)$, partial articular sided supraspinatus tears $(14.3 \%$ vs $.0 \%)$, labral heterogeneity $(71.4 \%$ vs $40.9 \%)$, frank labral tears $(28.6 \%$ vs $9.1 \%)$, intraarticular biceps signals $(14.3 \%$ vs. $.0 \%)$, and posterior superior humeral cysts $(85.7 \%$ vs $45.5 \%)$. No MRI findings were found to be significant predictors of the duration of time spent on the IL $(P=.279-.896)$. With respect to the receipt of future surgery, both partial articular-sided supraspinatus tears $(P=.035)$ and intraarticular biceps tendon signals $(P=.035)$ were associated with the receipt of future surgery (Table 2). It is noted, however, that only one patient ultimately required shoulder surgery, thereby limiting our assessment.

With respect to sabermetrics, the presence of labral heterogeneity on pre-signing MRI was associated with greater averages for total career pitches $(10,034.1 \mathrm{vs}$. $2,465.3 ; P=.039$ ). Additionally, the presence of a labral tear was associated with decreased ERA at 3 years $(2.15$ vs 3.86; $P=.002$ ), increased strikeouts per 9 innings at 2 years ( 10.9 vs $7.4 ; P=.043)$, and increased career strike out percentage $(25.6 \%$ vs. $19.6 \%, P=.032)$. Similarly, those with increased capsular signal were found to have decreased ERA at 5 years (2.34 vs 5.44;

Table 1. Variables in MRI Analysis

\begin{tabular}{|c|c|c|c|c|}
\hline Rotator Cuff & Labrum & $\begin{array}{c}\text { Capsular GH Internal } \\
\text { Rotation Deficit }\end{array}$ & Biceps & Humeral Head \\
\hline $\begin{array}{l}\text { Supraspinatus Tendon } \\
\text { Insertion Heterogeneity/ } \\
\text { Hyperintensity (B) }\end{array}$ & $\begin{array}{c}\text { Labral Heterogeneity/ } \\
\text { Hyperintensity (B) }\end{array}$ & $\begin{array}{r}\text { Presence of Increased } \\
\text { Capsular Signal (B) }\end{array}$ & $\begin{array}{l}\text { Biceps Signal } \\
\text { Extra-articular (B) }\end{array}$ & $\begin{array}{l}\text { Posterior Superior } \\
\text { Humeral Cyst (B) }\end{array}$ \\
\hline $\begin{array}{l}\text { Partial Articular Side } \\
\text { Signal (B) }\end{array}$ & $\begin{array}{l}\text { Labral Heterogeneity/ } \\
\text { Hyperintensity } \\
\text { Location (C) }\end{array}$ & & $\begin{array}{l}\text { Biceps Signal } \\
\text { Intra-articular (B) }\end{array}$ & $\begin{array}{l}\text { Posterior Superior } \\
\text { Humeral Cyst Size (N) }\end{array}$ \\
\hline $\begin{array}{l}\text { Partial Bursal Side } \\
\text { Signal (B) }\end{array}$ & Labral Tear (B) & & Biceps Tear (B) & Additional Findings (FT) \\
\hline Full Thickness Tear (B) & Labral Tear Location (C) & & & \\
\hline
\end{tabular}

Anatomic structures of interest and rubric of evaluated pathology in the MRI analysis.

$\mathrm{B}$, binary; C, categorical variable; FT, free text; N, numerical variable. 
Table 2. Relationship Between MRI Findings and Future IL Placement and Surgery

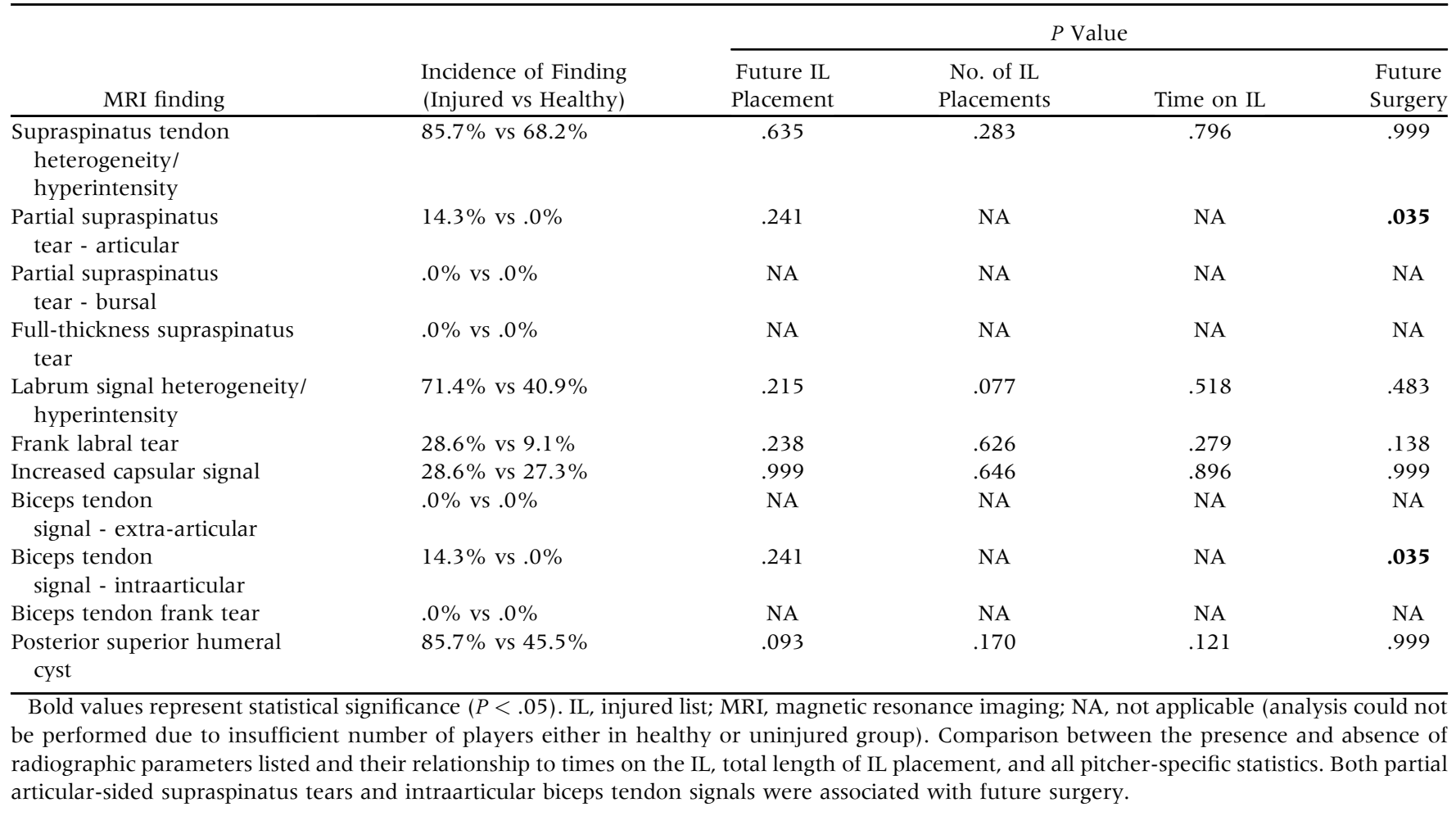

$P=.011)$, and increased field independent pitching metrics at 3 years $(4.4$ vs 3.5; $P=.022)$. Pitchers who were found to have a posterior superior humeral cyst on pre-signing MRI, in contrast to the labral or capsular findings noted, had decreased strikeout percentages per 9 innings at 3 years (6.6 vs 13.2; $P=.039$ ), decreased overall strikeout percentages at 2 years $(16.6 \%$ vs $23.2 \% ; P=.044)$, and decreased field independent pitching after their first-year pitching (3.1 vs 4.3; $P=$.046) (Table 4).

\section{Discussion}

The main finding of this study was that asymptomatic MRI findings may be useful predictors of various pitching performance metrics; however, these findings are not adequately predictive of either the frequency or duration of IL placement. Some specific associations

Table 3. Demographics of Included Pitchers

\begin{tabular}{lccc}
\hline \multicolumn{1}{c}{ Characteristic } & Injured $(n=7)$ & Healthy $(n=22)$ & $P$ Value \\
\hline Age (years) & $31.9 \pm 5.0$ & $27.1 \pm 5.0$ & $\mathbf{. 0 4 0}$ \\
Height (in) & $75.9 \pm 2.0$ & $75.4 \pm 2.2$ & .603 \\
Weight (lbs) & $208.6 \pm 21.4$ & $213.9 \pm 31.7$ & .682 \\
No. Games Played & $158.7 \pm 207.3$ & $122.0 \pm 146.9$ & .606 \\
Handedness (R/L) & $5 / 2$ & $15 / 7$ & .999
\end{tabular}

In, inches; lbs, pounds; R/L, right/left. Key demographics of included pitchers. Healthy pitchers were significantly younger than injured pitchers, with no other significant differences noted between the groups. include the presence of labral injury (i.e., heterogeneity, tear) or a posterior superior humeral cyst on pre-signing MRI being associated with increased earned-run averages (ERAs) and decreased strikeout rates (i.e., K/9 innings). Although articular-sided RTC tears and intra-articular injury to the LHBT was found to be associated with future shoulder surgery, limitations in sample size suggest that the presence of multiple shoulder pathologies (i.e., LHBT, labral, RTC) may be more predictive of future surgery, rather than any asymptomatic finding in isolation. These results may be best used to risk stratify pitchers at greatest risk of decreased performance metrics. Future studies, particularly those with increased power would likely benefit from combining MRI data across multiple teams or assessing pitchers through the MLB Health and Injury Tracking System (HITS) database, would be beneficial.

Asymptomatic MRI findings are becoming increasingly commonplace for professional athletes across sporting leagues (i.e., MLB, NFL, MLS, etc.) in the United States. ${ }^{17,18,20,21,28}$ Previous studies have detailed both radiographic and MRI findings commonly found on routine preseason imaging of the throwing shoulder in asymptomatic pitchers. $7,27,28$

Specifically, a study by Connor et al. demonstrated that the throwing shoulder in overhead athletes may have unique asymptomatic lesions, such as a Bennett lesions and RTC tears. ${ }^{29}$ Although the prevalence of these asymptomatic lesions of the shoulder and elbow 
Table 4. Relationship Between Radiologic Findings and Sabermetric Statistics

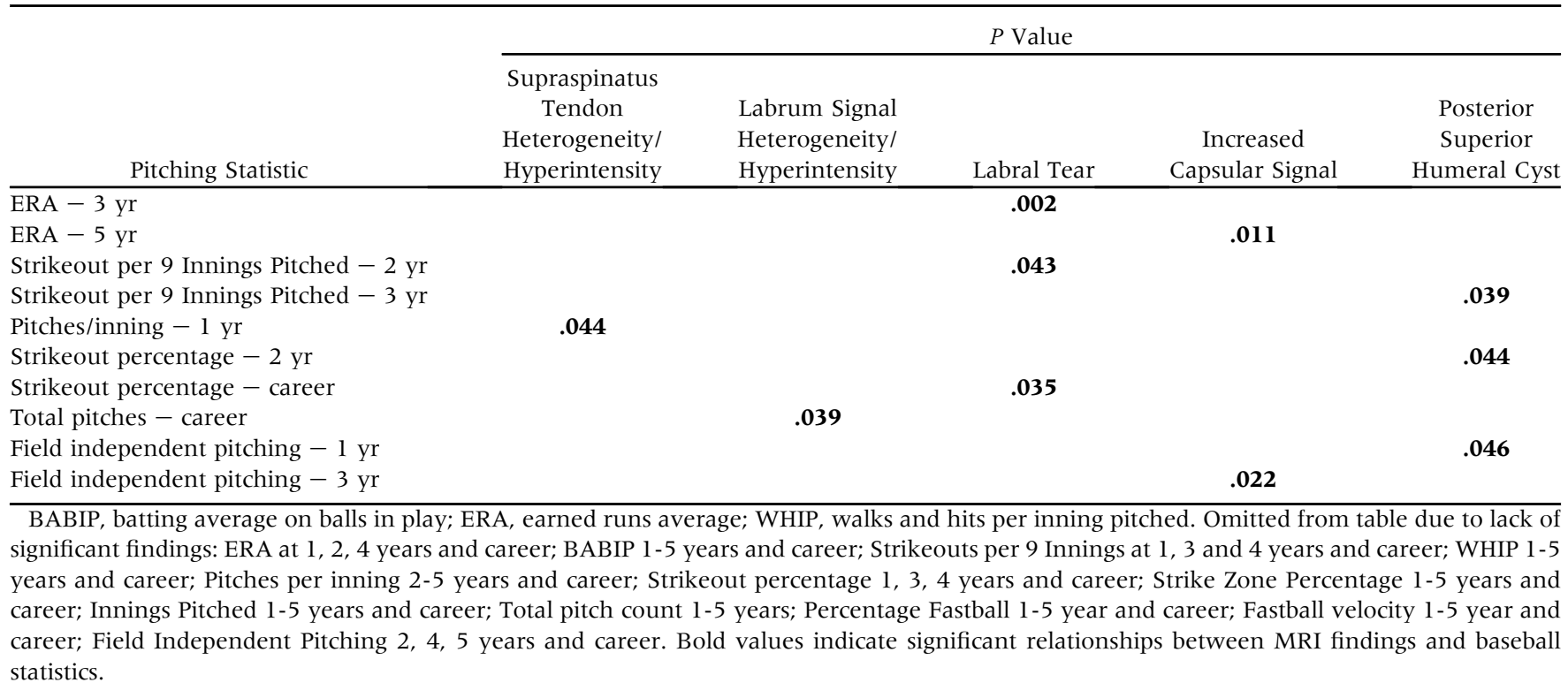

continue to be examined, a key question remains does the presence of these findings on MRI signal greater risk for future IL placement or future surgery? Consequently, can an MLB organization use this information to identify those at risk of injury, and potentially employ strategies (i.e., focused training, monitoring of pitch counts) to decrease future injury risk? The current study suggests that the presence of asymptomatic shoulder findings does not increase the risk of future IL placement. A similar single-team study by Wright et al. suggests that asymptomatic findings on shoulder radiographs of MLB pitchers do not predict time spent on the IL, but are correlated with the number of innings pitched. ${ }^{16}$ However, the current study also suggests that the presence of multiple shoulder-related changes on preseason MRI may place an individual at risk for future surgery. Wright's singleteam study reports a similar finding, in that the sum of radiographic shoulder findings correlated with the number of innings pitched. All in all, the current study suggests that asymptomatic shoulder findings may represent pitching-related wear on the body, and that injury risk may be related to the total burden of asymptomatic findings as opposed to the presence of isolated findings. Further studies must take into account two important limitations in the current literature: 1) significant heterogeneity among study designs with respect to the imaging findings examined, and 2) limited power in single-team case series. Accordingly, future studies may consider pooling data across singleteam case series or utilizing the MLB HITS to aggregate imaging findings across MLB pitchers.

Previous studies have suggested that asymptomatic degenerative changes in the throwing shoulder and elbow occur with greater frequency in pitchers with greater innings pitched. A single-team case series by Wright et al. found there to be a correlation between innings pitched and the presence of acromioclavicular (AC) joint findings, radial head osteophytes, or the sum of radiographic findings of the shoulder. ${ }^{16} \mathrm{~A}$ singleteam study by Lesniak et al. also found that the prevalence of articular-sided RTC tears, full-thickness RTC tears, and SLAP tears increases with increasing pitch counts. ${ }^{7}$ The current study adds to the work by Lesniak et al. by suggesting that earlier inflammatory changes in the RTC and labrum (i.e., signal heterogeneity) also increase as a function of innings pitched. Overall, current data suggest that certain radiographic and MRI findings of the throwing shoulder are associated with increased innings pitched, but they do not predict IL placement or the need for future surgery. This is in contrast to the elbow, where asymptomatic findings (i.e., UCL heterogeneity, UCL-partial tears, posteromedial impingement) have been linked to IL placement and the need for future surgery ${ }^{24}$ (Table 5).

Although previous literature has begun to examine the relationship between the presence of specific asymptomatic findings on elbow and shoulder MRI, ${ }^{7,16,24}$ the impact of these findings on pitching performance metrics is less clear. Although various MRI findings were found to be associated with decreased pitching performance (i.e., labral tear, capsular hyperintensity, humeral cyst), the presence of a posterior superior humeral cyst was most consistently associated with decreased performance, including increased ERA, decreased strikeout rates, and decreased fieldindependent pitching (FIP). The humeral head can develop cystic changes in the case of articular and RTC disease, and previous studies have demonstrated that overhead athletes may develop cystic structural lesions 
Table 5. Findings Correlated With Increased Innings Pitched

\begin{tabular}{|c|c|}
\hline Radiographic Findings & MRI Findings \\
\hline $\begin{array}{l}\text { Sum of radiographic findings } \\
\text { of the shoulder }\end{array}$ & Supraspinatus heterogeneity $^{1}$ \\
\hline $\begin{array}{l}\text { Acromioclavicular joint } \\
\text { findings }{ }^{2}\end{array}$ & Labral heterogeneity $^{1}$ \\
\hline Radial head osteophytes ${ }^{2}$ & $\begin{array}{l}\text { RTC tear (i.e., articular surface } \\
\text { tear, full-thickness tear) } \\
\text { Superior labrum anterior-to- } \\
\text { posterior (SLAP) tear }\end{array}$ \\
\hline
\end{tabular}

Imaging findings correlated with an increase in the number of innings pitched, as described in previous studies.

${ }^{1}$ Suggested by data from the current study.

${ }^{2}$ Suggested by data from Wright et al. ${ }^{34}$

${ }^{3}$ Suggested by data from Lesniak et al. ${ }^{21}$

in the shoulder, ${ }^{30-32}$ particularly at RTC tendon footprints. ${ }^{29,33,34}$ The current study suggests that the identification of a posterior superior humeral cyst in the throwing shoulder may represent a novel imaging marker predictive of decreased pitching performance in MLB pitchers. Although all players included in this study were asymptomatic, further studies should consider assessing strength (i.e., internal and external rotation), range of motion, pain, and sabermetric differences in players with and without evidence of a posterior superior humeral cyst.

\section{Limitations}

The current study is not without important limitations that all readers must consider. First, with respect to the study methodology, some MRI findings (e.g., RTC, labral tears) are more easily identified than others (e.g., capsular heterogeneity). In addition, there is the possibility of observer bias in the examination of MRIs known by readers to be asymptomatic. To address these limitations, the imaging findings examined in the current study represent a consensus statement among 3 independent reviewers, including two fellowshiptrained orthopaedic surgeons and one radiologist trained in musculoskeletal imaging. There was agreement among two reviewers on $>95 \%$ of imaging findings, and $<4 \%$ of imaging findings required a $3 \mathrm{rd}$ reviewer to act as a tiebreak. Second, the study is limited by its retrospective design and power $(n=41)$. Future studies should consider conducting similar analyses using data aggregated across multiple teams, such as the MLB's HITS. Third, certain limitations in data accuracy exist in using publicly available databases for the purpose of mining data related to IL placement and surgical intervention. However, many previous studies have utilized public data, $, 11,12,16$ most commonly verifying the data collected across two separate publicly available databases. Fourth, because of limitations in the medical data collected on the players included in the study, objective clinic data, such as strength and range of motion, is unavailable. Although patients may be asymptomatic, the association of specific findings with decreased performance begs the question if specific subclinical deficits in strength, range of motion or pain may exist between pitchers. Lastly, a pitcher was deemed to be "asymptomatic" if the MRI performed was at least 6 months prior to IL placement for any shoulder-related injury. Although arguments can be made in support of a longer period of time (i.e., l year), 6 months was deemed to be adequate on the basis of previous literature. ${ }^{24}$

Other important limitations include those associated with the use of performance metrics to assess pitching performance. Pitching performance is complex, and as such, although a pitcher may have a decreased strikeout percentage, lower pitch count, and decreased fastball speed, other metrics (i.e., ERA, WHIP, KK/walk ratio) may remain the same or even improve. Thus, it is difficult to draw conclusions on pitching performance with a sample size, as it is a multifaceted assessment best assessed with appropriate power. In addition, although we report significant associations between specific asymptomatic findings and the need for future surgery, this was in only one player with complex shoulder pathology, suggesting injury to multiple structures. Thus, we are unable to make any statement regarding asymptomatic MRI findings and the need for future surgery. Moreover, the injured cohort is significantly older than the noninjury cohort, which is a confounding factor on pitcher performance and may contribute to some of the differences in pitching performance we found (31.9 vs. 27.1 years).

\section{Conclusion}

Although there was a significant difference in the percent of various radiographic findings between the injured and healthy cohort, no MRI findings were predictive of future IL placement or duration of placement. The presence of a posterior superior humeral cyst was associated with decreased strikeout rates at 2 and 3 years, the presence of a labral tear was associated with decreased ERA at 3 years and decreased career strikeout percentages, and increased capsular signal was associated with decreased 5-year ERA.

\section{References}

1. Dillman CJ, Fleisig GS, Andrews JR. Biomechanics of pitching with emphasis upon shoulder kinematics. J Orthop Sports Phys Ther 1993;18:402-408.

2. Fleisig GS, Andrews JR, Dillman CJ, Escamilla RF. Kinetics of baseball pitching with implications about injury mechanisms. Am J Sports Med 1995;23:233-239.

3. Weber AE, Kontaxis A, O'Brien SJ, Bedi A. The biomechanics of throwing: Simplified and cogent. Sports Med Arthrosc Rev 2014;22:72-79.

4. Wilk KE, Meister K, Andrews JR. Current concepts in the rehabilitation of the overhead throwing athlete. Am J Sports Med 2002;30:136-151. 
5. Gyftopoulos S, Recht M. The throwing shoulder: The common injuries and their underlying mechanisms. Semin Musculoskelet Radiol 2014;18:404-411.

6. Conte S, Requa RK, Garrick JG. Disability days in major league baseball. Am J Sports Med 2001;29:431-436.

7. Lesniak BP, Baraga MG, Jose J, Smith MK, Cunningham S, Kaplan LD. Glenohumeral findings on magnetic resonance imaging correlate with innings pitched in asymptomatic pitchers. Am J Sports Med 2013;41:2022-2027.

8. MLB positional payrolls. 2019. https://www.spotrac.com/ $\mathrm{mlb} /$ positional/. Accessed December 27, 2021

9. Erickson BJ, Chalmers PN, Bush-Joseph CA, Romeo AA. Predicting and preventing injury in Major League Baseball. Am J Orthop (Belle Mead NJ) 2016;45:152-156.

10. Saltzman BM, Mayo BC, Higgins JD, et al. How many innings can we throw: Does workload influence injury risk in Major League Baseball? An analysis of professional starting pitchers between 2010 and 2015. J Shoulder Elbow Surg 2018;27:1386-1392.

11. Erickson BJ, Chalmers PN, Axe MJ, Romeo AA. Exceeding pitch count recommendations in Little League Baseball increases the chance of requiring Tommy John surgery as a professional baseball pitcher. Orthop J Sports Med 2017;5:2325967117695085.

12. Keller RA, Mehran N, Marshall NE, et al. Major League pitching workload after primary ulnar collateral ligament reconstruction and risk for revision surgery. J Shoulder Elbow Surg 2017;26:288-294.

13. Keller RA, Marshall NE, Guest JM, Okoroha KR, Jung EK, Moutzouros V. Major League Baseball pitch velocity and pitch type associated with risk of ulnar collateral ligament injury. J Shoulder Elbow Surg 2016;25:671-675.

14. Chalmers PN, Erickson BJ, Ball B, Romeo AA, Verma NN. Fastball pitch velocity helps predict ulnar collateral ligament reconstruction in major league baseball pitchers. Am J Sports Med 2016;44:2130-2135.

15. Camp CL, Zajac JM, Pearson DB, et al. Decreased shoulder external rotation and flexion are greater predictors of injury than internal rotation deficits: Analysis of 132 pitcher-seasons in professional baseball. Arthroscopy 2017;33:1629-1636.

16. Wright RW, Steger-May K, Klein SE. Radiographic findings in the shoulder and elbow of Major League Baseball pitchers. Am J Sports Med 2007;35:1839-1843.

17. Kaplan LD, Schurhoff MR, Selesnick H, Thorpe M, Uribe JW. Magnetic resonance imaging of the knee in asymptomatic professional basketball players. Arthroscopy 2005;21:557-561.

18. Silvis ML, Mosher TJ, Smetana BS, et al. High prevalence of pelvic and hip magnetic resonance imaging findings in asymptomatic collegiate and professional hockey players. Am J Sports Med 2011;39:715-721.

19. de Jesus JO, Parker L, Frangos AJ, Nazarian LN. Accuracy of MRI, MR arthrography, and ultrasound in the diagnosis of rotator cuff tears: A meta-analysis. Am J Roentgenol 2009;192:1701-1707.

20. Iannotti JP, Zlatkin MB, Esterhai JL, Kressel HY, Dalinka MK, Spindler KP. Magnetic resonance imaging of the shoulder. Sensitivity, specificity, and predictive value. J Bone Joint Surg Am 1991;73:17-29.

21. Collin P, Yoshida M, Delarue A, et al. Evaluating postoperative rotator cuff healing: Prospective comparison of MRI and ultrasound. Orthop Traumatol Surg Res 2015;101: S265-S268.

22. Jost B, Zumstein M, Pfirrmann CW, Zanetti M, Gerber C. MRI findings in throwing shoulders: Abnormalities in professional handball players. Clin Orthop Relat Res 2005: 130-137.

23. Gutierrez NM, Granville C, Kaplan L, Baraga M, Jose J. Elbow MRI findings do not correlate with future placement on the disabled list in asymptomatic professional baseball pitchers. Sports Health 2017;9:222-229.

24. Garcia GH, Gowd AK, Cabarcas BC, et al. Magnetic resonance imaging findings of the asymptomatic elbow predict injuries and surgery in major league baseball pitchers. Orthop J Sports Med 2019;7:2325967118818413. doi: $10.1177 / 2325967118818413$.

25. "Fangraphs Baseball: Baseball Statistics and Analysis." FanGraphs Baseball | Baseball Statistics and Analysis, Major League Baseball, www.fangraphs.com/. Accessed December 27, 2021

26. "MLB Stats, Scores, History, \& Records." Baseball Reference, Major League Baseball, www.baseball-reference.com/. Accessed December 27, 2021

27. Del Grande F, Aro M, Jalali Farahani S, Cosgarea A, Wilckens J, Carrino JA. High-resolution 3-T magnetic resonance imaging of the shoulder in nonsymptomatic professional baseball pitcher draft picks. J Comput Assist Tomogr 2016:40:118-125.

28. Miniaci A, Mascia AT, Salonen DC, Becker EJ. Magnetic resonance imaging of the shoulder in asymptomatic professional baseball pitchers. Am J Sports Med 2002;30: 66-73.

29. Connor PM, Banks DM, Tyson AB, Coumas JS, D'Alessandro DF. Magnetic resonance imaging of the asymptomatic shoulder of overhead athletes: A 5-year follow-up study. Am J Sports Med 2003;31:724-727.

30. Roger B, Skaf A, Hooper AW, Lektrakul N, Yeh L, Resnick D. Imaging findings in the dominant shoulder of throwing athletes: Comparison of radiography, arthrography, CT arthrography, and MR arthrography with arthroscopic correlation. Am J Roentgenol 1999;172: 1371-1380.

31. Mlynarek RA, Lee S, Bedi A. Shoulder injuries in the overhead throwing athlete. Hand Clin 2017;33:19-34.

32. Meister $K$. Injuries to the shoulder in the throwing athlete. Part one: Biomechanics/pathophysiology/classification of injury. Am J Sports Med 2000;28:265-275.

33. Pearsall AWT, Bonsell S, Heitman RJ, Helms CA, Osbahr D, Speer KP. Radiographic findings associated with symptomatic rotator cuff tears. J Shoulder Elbow Surg 2003;12:122-127.

34. Beitzel K, Beitzel KI, Zandt JF, et al. Premature cystic lesions in shoulders of elite junior javelin and volleyball athletes: a comparative evaluation using 3.0 Tesla MRI. J Shoulder Elbow Surg 2013;22:792-799. 